\title{
The Effect of a Cognitive Behavioral Treatment Program for Male Young Delinquents in Guangzhou: A Pilot Study
}

\author{
Jinwu Zhang ${ }^{1} \&$ Yan Zhang ${ }^{2}$ \\ ${ }^{1}$ Department of Sociology, University of Macau, Macau, China \\ ${ }^{2}$ College of Asia \& Pacific, Australian National University, Canberra, Australian \\ Correspondence: Jinwu Zhang, Department of Sociology, University of Macau, Macau, China. E-mail: \\ sifajuzhangjinwu@126.com
}

Received: July 14, 2016

doi:10.5539/ijps.v8n3p123

\author{
Accepted: July 29, $2016 \quad$ Online Published: August 2, 2016 \\ URL: http://dx.doi.org/10.5539/ijps.v8n3p123
}

\begin{abstract}
Pro-criminal attitudes and inefficiency in social skills or problem-solving skills are associated with criminal conducts. Targeting on these factors, Cognitive-Behavior Treatment (CBT) programs are effective interventions for adult and young offenders. However, the effectiveness of CBT programs in Chinese correctional facilities is unknown. The present study, as a pilot one, evaluates a CBT program consisting of six sessions to treat young delinquents in South China. In Guangzhou, 60 male delinquents were divided into experimental and comparison group. Problem-solving skills, social skills and pro-criminal attitudes were measured and compared before and after the program for both groups. Measured by Social Maladjustment Scale (SOC) and General Self-efficacy Scale (GSES), the experimental group showed significant improvements in social skills and problem solving skills, while those of the comparison group remained constant. The results of the pilot study were encouraging and demonstrating the potential of CBT programs to be effective treatment for young delinquents in South China. Implications for future research and cross-cultural generability of CBT are discussed.
\end{abstract}

Keyword: evaluation, CBT, China, cross-cultural generability

\section{Introduction}

There is a large body of research about "What works" for offender rehabilitation over the past decades. For many effective correctional programs, cognition issues and cognitive-behavioral methods were addressed and used (MacKenzie, 2013; Sherman, Gottfredson, MacKenzie, Eck, Reuter, \& Bushway, 1998). Most cognitive-Behavioral Treatment (CBT) programs are based on either cognitive restructuring theory or cognitive skills theory aiming to change the offenders' cognition and their behaviors (Golden, 2002; Marshall, Robinson, \& Cahill, 2004), and considerable literature has provided positive empirical evidence for CBT programs in western countries (Lipsey \& Cullen, 2007; Andrews \& Bonta, 1994; Andrews, Bonta, \& Hoge, 1990; Cullen \& Gendreau, 2001; Andrews \& Bonta, 1994; Andrews, Bonta, \& Hoge, 1990; Cullen \& Gendreau, 2001). To measure the effectiveness of CBT programs, the major standard is their impact on recidivism rates (Van der Put, Stams, Hoeve, Deković, Spanjaard, Van der Laan, \& Barnoski, 2012; Bush, 1995; Cullen \& Gendreau, 2001; Golden, 2002; Little et al., 1994), and research showed that recidivism rates of experimental group are 15 to $31.2 \%$ lower than that of comparison group (Landenberger \& Lipsey, 2005; Bush, 1995; Little, Robinson, \& Burnette, 1994), for both young and adult offenders in prisons or on probation (Bush et al., 2002; Forde, 2005; Golden, 2002). Meanwhile, improvements in offenders' attitudes, social skills, and problem-solving skills were also used (Chui \& Nellis, 2003; Forde, 2005; Golden, 2002; Bogestad, Kettler, \& Hagan, 2010; McGlynn, Hahn, \& Hagan, 2013).

The purpose of Cognitive behavioral treatment programs is to improve the offenders' attitudes, social skills and problem-solving skills, thus lowering their recidivism. Improvements in attitudes and social skills are important because research has shown that pro-criminal attitudes and low social skills are correlates of criminal conducts (Andrews \& Bonta, 1994). Also, this is coincident with the risk-need principles, which suggest that interventions and services should target the factors that will lead to higher risk of offending or reoffending (Andrews, 1995; Andrews \& Bonta, 1994; Bonta, 1996). Listed in their significance, pro-criminal attitudes, antisocial peers, personality factors such as weak socialization and weak problem-solving skills, a history of antisocial behavior, family problems, and education problems are correlates to criminal activities (Andrews \& Bonta, 1994; Marshall 
et al., 2004). So CBT programs often target pro-criminal attitudes, social skills deficiencies, and problem-solving deficiencies for intervention.

Most findings on "What works" stem from North America, and it may be unclear about their generability to other cultures and countries with different cultural contexts (Koehler, Lösel, Akoensi, \& Humphreys, 2013). Scientific evidence is needed to evaluate the cross-cultural generability of CBT programs to treat offenders in countries with different cultures, such as China. When developing interventions and services which are based on Western scientific approaches in non-Western world, the difficulty in making culture and language-specific adaptations is a major obstacle (Bolman, 1968). The delivery of CBT involves such competencies as good interpersonal relational skills and cross-cultural sensitivity (Newman, 2010), and proper technical adjustments and culture-specific modifications are needed for diversified ethnic and cultural backgrounds for successful treatment outcome (Tseng, 2004; Newman, 2010).

Currently, structural rehabilitation programs for young delinquents are scare in China (Wong, 2004). Meanwhile, no published report has been found regarding the implementation and evaluation of CBT program for treating adult offenders or young delinquents in Chinese correctional field. On the other hand, most offenders in China, including young delinquents, also show similar characteristics as pro-criminal attitudes, weak social skills, and weak problem-solving skills (Chen, 2009; Zhang Chunmei, \& Zou, 2006), which make them suitable targets for CBT interventions. Chinese young delinquents' pro-criminal attitudes usually include low self-control, aggressiveness, impulsivity, and pro-criminal attitudes and are strongly correlating to delinquency (Duan \& Huang, 2006; Jing, 2009). The above studies provide evidence for the need of different rehabilitation programs and models in Chinese correctional field, and CBT might fit.

To deliver CBT programs in China, materials and other evidence from western countries should be considered, but how to ensure the quality and modality of such programs after translation would be a key issue. This pilot study aims to evaluate a brief intervention program, thus investigating the effectiveness and cross-cultural generability of CBT in Guangzhou City, South China. The participants were divided into experimental and comparison group, and their problem-solving skills, social skills and pro-criminal attitudes were measured before (Time 1) and after (Time 2) the CBT program.

\section{Method}

\subsection{Participants}

When the study was conducted, there were 75 male delinquents and no female subjects in Guangzhou young Shelter, which is located in Guangzhou City, South China. The Shelter is supervised by the Guangzhou Judicial Bureau, and is responsible for the detention of young delinquent with minor offenses. According to the Penal Code and the judicial practice in China, if a suspect conducted offense under age 18 and was arrested and sentenced above age 18, he or she would still be treated as young delinquent. The authority of the Shelter provided a list of 75 male delinquents whose sentence length were close to the end. 60 participants were selected from the list by picking a name from every adjacent two in the list.

The first 30 were assigned into the experimental group while the rest 30 to the control group. The experimental group was admitted into the CBT program, whereas the control group was not. All participants had no mental disorder and would be released in the next one to two months (Note 1). Among the 60 delinquents, 50 (83.3\%) were housed because of theft, $9(15 \%)$ and $1(1.7 \%)$ were snatch and robbing respectively. The majority of participants committed minor offence. As comparison, juvenile participants in two western studies are adjudicated offender and most have numerous acts of violent delinquency (Bogestad et al., 2010; McGlynn et al., 2013).

Participants in the experiment group were informed by the officers that the CBT program was part of their education courses and would earn credits for taking it. The control group would take their normal education courses as before.

Table 1. Demographics information of participants $(\mathrm{N}=60)$

\begin{tabular}{lllll}
\hline & Min & Max & M & SD \\
\hline Age & 14 & 22 & 16.9 & 1.884 \\
Education years & 2 & 11 & 7.0 & 1.647 \\
Years in the Shelter & 1 & 2 & 1.113 & 0.26 \\
\hline
\end{tabular}




\subsection{Program Structure}

The CBT program evaluated in the present study is designed with reference to some CBT programs in U.S., such as the Thinking for a Change developed by National Institute of Corrections (Golden, 2002) or Challenges implemented in Wisconsin (Bogestad et al., 2010). The CBT program focuses on targeting offender's pro-criminal patterns, social skill deficiencies, and problem-solving deficiencies, trying to replace the offenders' pro-criminal attitudes with new thinking patterns, and improve their social and problem-solving skills, and thus, helping them avoid new criminal behavior, misconducts, or technical violations.

As a pilot study, the CBT program is consist of six sessions with core concepts of cognitive restructuring, problem-solving skill and social skill training. Six sessions are in group format, and the group size is limited to a maximum of 15 youths. At the beginning is the Preparation session with ice-breaking activities, and participants administer the instruments (Time 1).

Session 1 introduces the overview of the CBT program, and scenarios are used to reveal the relationship between thinkings and actions.

Session 2 provides practice about how to recognize pro-criminal that leads to trouble, and listening and feedback-giving skills. Session 3 Skills on finding new thinking and introduces problem-solving skills.

Session 4 introduces the framework of problem-solving skills, and teaches Steps 1 and 2 of problem-solving skills, and Session 5 teaches Steps 3 and 4 of problem-solving skills.

Session 6 teaches Steps 5 and 6 of problem-solving skills, following by group share, and participants would fulfill the instruments (Time 2) and evaluation forms.

Details of the six sessions are shown in Table 2:

Table 2. Summary of the CBT program

\begin{tabular}{|c|c|c|}
\hline & Description & Content \\
\hline Preparation session & $\begin{array}{l}\text { Participants fulfill the instruments (Time } \\
\text { 1) }\end{array}$ & $\begin{array}{l}\text { Introducing each other, ice-breaking } \\
\text { activities }\end{array}$ \\
\hline Session 1 & $\begin{array}{l}\text { Introduction and overview of the CBT } \\
\text { program. }\end{array}$ & $\begin{array}{l}\text { - How to know yourself } \\
\text { - Explanation about relationship } \\
\text { between thinking and behaviors } \\
\text { - Four scenarios and group discussions } \\
\text { in different parts of the session }\end{array}$ \\
\hline Session 2 & $\begin{array}{l}\text { How to recognize pro-criminal thinking } \\
\text { pattern that leads to trouble and listening } \\
\text { and feedback-giving skills }\end{array}$ & $\begin{array}{l}\text { - Watch and discuss a scene play about } \\
\text { interpersonal conflict } \\
\text { - Use thinking report to identify } \\
\text { pro-criminal thoughts } \\
\text { - Practice and discussion about } \\
\text { relationship of pro-criminal thoughts, } \\
\text { beliefs, and pro-criminal behaviors }\end{array}$ \\
\hline Session 3 & $\begin{array}{l}\text { Skills on finding new thinking and } \\
\text { introduces problem-solving skills }\end{array}$ & $\begin{array}{l}\text { - Watch and participate in scene plays } \\
\text { to learn skills for replacing pro-criminal } \\
\text { thoughts with new ideas } \\
\text { - Introduction about six steps of } \\
\text { problem-solving skills } \\
\text { - Discussion about using the } \\
\text { problem-solving skills to replace } \\
\text { pro-criminal thoughts }\end{array}$ \\
\hline Session 4 & & $\begin{array}{l}\text { - Identify pro-criminal thoughts } \\
\text { - Describe the problem }\end{array}$ \\
\hline Session 5 & Steps 3 and 4 of problem-solving skills & $\begin{array}{l}\text { - Gather and analyze information, then } \\
\text { set the goal } \\
\text { - Think about different choices and their } \\
\text { consequences }\end{array}$ \\
\hline Session 6 & $\begin{array}{l}\text { Steps } 5 \text { and } 6 \text { of problem-solving skills } \\
\text { and group share } \\
\text { Participants fulfill the instruments (Time } \\
\text { 2) and evaluation forms }\end{array}$ & $\begin{array}{l}\text { - Make a choice } \\
\text { - Take an action } \\
\text { - Sharing experience and group } \\
\text { discussion }\end{array}$ \\
\hline
\end{tabular}




\subsection{Instruments}

How to measure the participants' social skills, and problem-solving skills before (Time 1) and after the program (Time 2) is the key point in the present study.

The present study used Criminal Sentiments Scale (CSS) to measure participants' pro-criminal attitudes. The program focused on training of problem-solving skills, but cognitive restructuring processes were also involved in the first two sessions, so the participants should also be measured for pro-criminal attitudes, which are interchangeable to pro-criminal thinking patterns (Golden, 2002). CSS is a 41-item self-report scale that measures pro-criminal attitudes, values, and beliefs related to criminal activity, police, law, courts and criminal peers with reliability ranging from 0.72 to 0.89 (Gendreau, Grant, Leipciger, \& Collins, 1979; Golden, 2002), and was translated into Chinese in the present study. Estimated by Cronbach's alpha, the internal consistency reliability of the Chinese version of CSS was 0.898 .

Social maladjustment Scale (SOC) was used to measure the participants' social skills. SOC comprises 27 items selected from the MMPI for screening individual's social skills and self-attitudes by asking the respondents regarding how they feel in a given public scenario, whose reliability and validity have been reported (Ji \& Dai, 2004). Higher scores indicate weaker social skills. Estimated by Cronbach's alpha, the internal consistency reliability of SOC for the present study was 0.722 .

General Self-Efficacy Scale (GSES) was used to measure participants' problem-solving skills. GSES comprises 10 items measured using Likert scale from 1 (Not at all true) to 4 (Exactly true) and is used broadly in many countries, including China, with sound reliability and validity (Schwarzer, Bäßler, Kwiatek, Schröder, \& Zhang, 1997; Wang \& Liu, 2000). Higher scores indicate better problem-solving skills. Estimated by Cronbach's alpha, the internal consistency reliability of GSES for the present study was 0.636 .

\subsection{Procedures}

The manual for the six sessions of the CBT was written and three registered social workers were trained. Handout materials for the courses were also prepared.

When participants in the experimental group were confirmed, they were informed by the officers and consent were obtained. In the preparation session, participants administered the pretest measurements (Time 1), and some ice-breaking exercises were delivered.

Group sessions took place three times in two weeks, 2 hours each time, so each experimental group finished the whole six courses over a four-week period in a classroom in the shelter. In the last session, the participants administered the same measurements (Time 2) and the evaluation form for facilitator performance.

For the 30 participants of the comparison group, they would also be informed by the officers and finished the measure at Times 1 and 2. During the program period, the experimental and comparison group were not separated and conducted other routine activities in the shelter as usual.

\subsection{Data Analyses}

To test the effect of the CBT program on the three scales, we first used independent $t$ test to compare the differences of CSS, SOC and GSES before and after the program for experimental and comparison group respectively. All $p$ values are two-sided, and $p<0.05$ was determined as statistically significant.

Secondly, post hoc power analyses were conducted because of the small sample size. We calculated the effect sizes of the t tests using Cohen's d (Cohen, 1988), and used G* power computer software (Faul, Erdfelder, Lang, \& Buchner, 2007) for the statistical power. As Cohen (1988) stated, the effect size is the degree that the null hypothesis is false, and "The power of a statistical test of a null hypothesis is the probability that it will lead to the rejection of the null hypothesis" (emphasis by the author).

Thirdly, we used multiple regression analysis to test the relationship between group status and changes on CSS, SOC and GSES, controlling for age. Changes on CSS, Changes on SOC and Changes on GSES were used as dependent variables in the multiple regression models, respectively, i.e., one in a model. Changes were calculated by the differences between before and after scores for every participant. Group status (experimental or comparison) served as independent variable in the three models, controlling for age. 


\section{Results}

\subsection{Criminal Sentiments Scale (CSS)}

There was no significant differences between group outcomes for CSS. For experimental group, mean pretest score was $44.2(\mathrm{SD}=8.54)$, and mean post-test score was $42.13(\mathrm{SD}=8.37)$. T test revealed that there is no significant difference between pre- and post-test scores for experimental group $(\mathrm{N}=30)$, with the effect size of 0.24 and the power of $0.36, \alpha$ (Type I error) $=.05$. To achieve $80 \%$ power to detect the 0.24 effect size, we would need 107 participants in experimental group. For comparison group, mean pretest score was $43.6(\mathrm{SD}=10.11)$ and mean post-test score was $44.5(\mathrm{SD}=9.08)$. $\mathrm{T}$ test revealed that there is no significant difference for pre- and post scores among comparison group $(\mathrm{N}=30$ ), with the effect size of 0.01 and the power of 0.12 , $\alpha$ (Type I error) $=.05$.

Table 3. Differences and power between pre-post scores of CSS

\begin{tabular}{|c|c|c|c|c|c|c|c|}
\hline & \multicolumn{2}{|c|}{ Before treatment } & \multicolumn{2}{|c|}{ After treatment } & \multirow{2}{*}{$\mathrm{t}$} & \multirow{2}{*}{$\begin{array}{l}\text { Effect Size } \\
\text { (Cohen's d) }\end{array}$} & \multirow{2}{*}{ Power } \\
\hline & $\mathrm{M}$ & SD & M & $\mathrm{SD}$ & & & \\
\hline Experimental group & 44.2 & 8.54 & 42.13 & 8.37 & 1.5 & 0.24 & 0.36 \\
\hline Comparison group & 43.6 & 10.11 & 44.5 & 9.08 & -1.25 & 0.01 & 0.12 \\
\hline
\end{tabular}

$* \mathrm{P}<0.05, * * \mathrm{P}<0.01, * * * \mathrm{P}<0.001$.

\subsection{Social Maladjustment Scale (SOC)}

For experimental group $(\mathrm{N}=30)$, mean pretest score was $15.50(\mathrm{SD}=4.25)$ and mean post-test score was 13.60 $(\mathrm{SD}=4.62), \mathrm{t}=2.495, p<0.05$, with the effect size of 0.45 and the power of $0.77, \alpha$ (Type I error) $=.05$. To achieve $80 \%$ power to detect the 0.45 effect size, we would need 32 participants in experimental group. Experimental group obtained significant change in SOC scores after receiving the CBT program, indicating improvement in social skills. For comparison group $(\mathrm{N}=30)$, mean pretest and post-test scores were $13.20(\mathrm{SD}=4.62)$ and 12.93 $(\mathrm{SD}=4.81)$, which has no significant difference, with the effect size of 0.06 and the power of $0.09, \alpha$ (Type I error $=.05$. Experimental group had significant change after treatment, whereas the control group remains constant.

Table 4. Differences and power between pre-post scores of SOC

\begin{tabular}{|c|c|c|c|c|c|c|c|}
\hline & \multicolumn{2}{|c|}{ Before treatment } & \multicolumn{2}{|c|}{ After treatment } & \multirow{2}{*}{$\mathrm{t}$} & \multirow{2}{*}{$\begin{array}{l}\text { Effect Size } \\
\text { (Cohen's d) }\end{array}$} & \multirow{2}{*}{ Power } \\
\hline & $\mathrm{M}$ & $\mathrm{SD}$ & $\mathrm{M}$ & SD & & & \\
\hline Experimental group & 15.50 & 4.249 & 13.60 & 4.627 & $2.499^{*}$ & 0.45 & 0.77 \\
\hline Comparison group & 13.20 & 4.627 & 12.93 & 4.813 & 0.549 & 0.06 & 0.09 \\
\hline
\end{tabular}




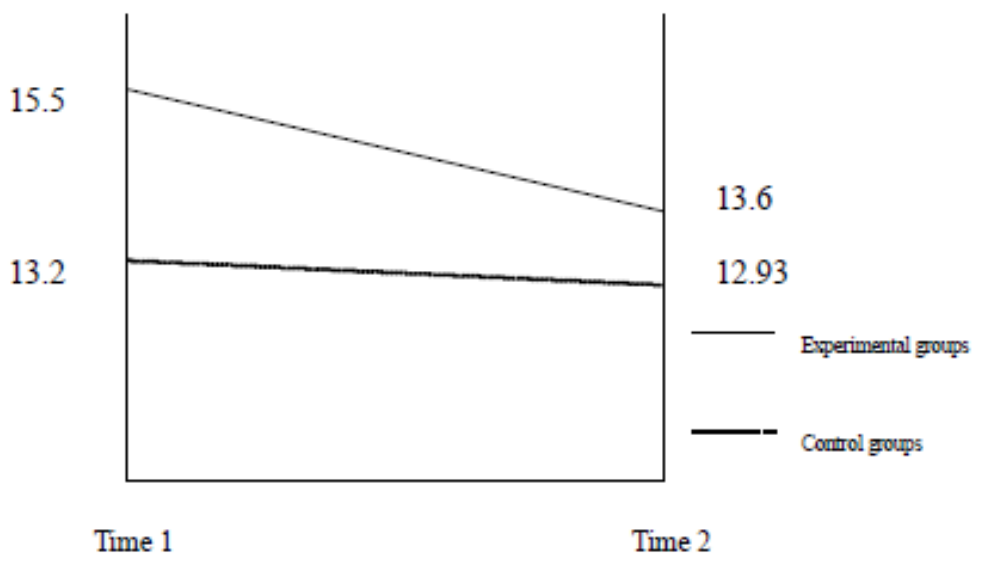

Figure 1. Pre-post scores of SOC

\subsection{General Self-Efficacy Scale (GSES)}

For experimental group $(\mathrm{N}=30)$, mean pretest and post-test scores were $23.87(\mathrm{SD}=4.175)$ and $28.03(\mathrm{SD}=5.049)$, $\mathrm{t}=5.165, p<0.001$, with the effect size of 0.82 and the power of 0.99 , $\alpha$ (Type I error) $=.05$, revealing that experimental group had improvement in problem-solving skills. For comparison group $(\mathrm{N}=30)$, mean pretest and post-test scores were $22.60(\mathrm{SD}=5.05)$ and $23.07(\mathrm{SD}=5.43)$, which has no significant difference, with the effect size of 0.09 and the power of $0.12, \alpha$ (Type I error) $=.05$.

Table 5. Differences and power between pretest and post-test scores of GESE

\begin{tabular}{|c|c|c|c|c|c|c|c|}
\hline & \multicolumn{2}{|c|}{ Before treatment } & \multicolumn{2}{|c|}{ After treatment } & \multirow{2}{*}{$\mathrm{t}$} & \multirow{2}{*}{$\begin{array}{l}\text { Effect Size } \\
\text { (Cohen's d) }\end{array}$} & \multirow{2}{*}{ Power } \\
\hline & $\mathrm{M}$ & SD & $\mathrm{M}$ & $\mathrm{SD}$ & & & \\
\hline Experimental group & 23.87 & 4.175 & 28.03 & 5.049 & $5.165 * * *$ & 0.82 & 0.99 \\
\hline Comparison group & 22.60 & 5.049 & 23.07 & 5.432 & 1.027 & 0.09 & 0.12 \\
\hline
\end{tabular}

$* \mathrm{P}<0.05, * * \mathrm{P}<0.01, * * * \mathrm{P}<0.001$.

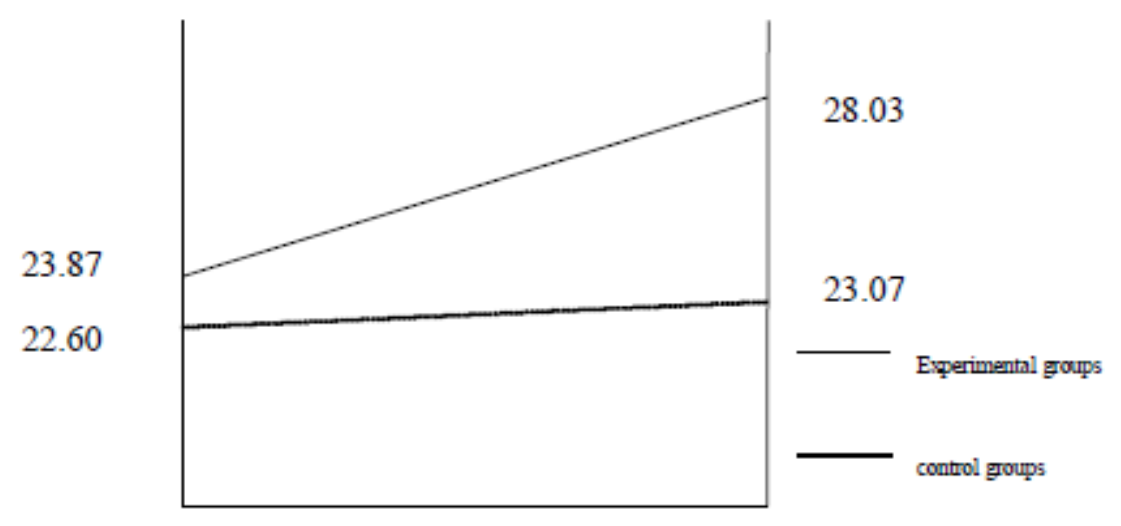

Time 1

Time 2

Figure 2. Pre-post scores of GSES 


\subsection{Prediction of Treatment Results}

As presented by Table 6, mean of Changes on CSS, Changes on SOC and Changes on GSES were -.88 $(\mathrm{SD}=7.66), 1.08(\mathrm{SD}=3.48)$ and $2.32(\mathrm{SD}=4.01)$ for all participants.

Age was not associated with Changes on CSS, Changes on SOC and Changes on GSES. In Model 2, there was negative association between group status and Changes on $\operatorname{SOC}\left(\mathrm{B}=-.280, p \leq 0.01\right.$, adjusted $\left.\mathrm{R}^{2}=.033\right)$, and negative association was also found in Model 3 between group status and Changes on GSES ( $\mathrm{B}=-.466, p \leq 0.001$, adjusted $\mathrm{R}^{2}=.188$ ), as shown in Table 7 . Given that experimental group was coded as 1 and comparison group coded as 2, such negative associations indicated that being a member of comparison group would have less likelihood to obtain changes on SOC and GSES, or being a member of experimental group would have higher likelihood to obtain changes on SOC and GSES.

Table 6. Descriptive statistics of dependent variables

\begin{tabular}{cccccccc}
\hline & \multicolumn{2}{c}{ Changes on CSS } & \multicolumn{2}{c}{ Changes on SOC } & \multicolumn{2}{c}{ Changes on GSES } \\
\cline { 2 - 7 } & $\mathrm{M}$ & $\mathrm{SD}$ & $\mathrm{M}$ & $\mathrm{SD}$ & $\mathrm{M}$ & $\mathrm{SD}$ \\
\hline All participants $(\mathrm{N}=60)$ & -.88 & 7.66 & 1.08 & 3.48 & 2.32 & 4.01 \\
\hline
\end{tabular}

Table 7. Multiple regression analysis with variables predicting treatment results

\begin{tabular}{lccc}
\hline & Model 1 & Model 2 & Model 3 \\
\cline { 2 - 4 } & Changes on CSS & Changes on SOC & Changes on GSES \\
\hline \multicolumn{1}{c}{$\begin{array}{l}\text { Explanatory variables } \\
\text { Age }\end{array}$} & -.100 & .108 & .027 \\
Group Status & & & $-.466^{* * *}$ \\
$\quad \begin{array}{l}\text { (Experimental group coded as 1, } \\
\text { comparison group coded as 2) } \\
\mathrm{R}^{2} \text { adjusted }\end{array}$ & .244 & $-.280^{*}$ & \\
\hline
\end{tabular}

$* \mathrm{P} \leq 0.05, * * \mathrm{P} \leq 0.01, * * * \mathrm{P} \leq 0.001$.

\section{Discussion}

The assumptions and theories of CBT programs are well established in western countries and might work in Chinese prisons and probation system because the generability of human cognitive and behaviors exist. However, there also exist specific characteristics and patterns of cognition and behaviors in different cultures. Participants in CBT programs will experience processes of developing and learning new thinking patterns and problem-solving skills. Although basic psychological processes are common in all human beings, the development and display of psychological characteristics are influenced by culture, allowing behavioral similarities and differences across human groups (Berry, 2002). CBT programs might work in different cultural context.

The experimental group obtained better scores in SOC and GESE at Time 2, whereas the control group remained constant at Times 1 and 2, indicating that participants' social skills and problem-solving skills are amendable in the group setting of the six-session CBT program. SOC and GESE were used in the present study because they had been tested in China before, and stable validity and reliability for both scales were reported. The present study found no difference between groups using CSS for pro-criminal attitudes, which is not surprising as the CBT program focuses on teaching problem-solving skills. CSS mainly asks the participants' thinking and attitudes toward law, court and police, for example asking how do they think about such statement as "Policemen are just as crooked as the people they arrest" or "Almost any jury can be fixed". However, how to think about law, court and police was not fully covered in the CBT programs. In the CBT program, the cognitive restructuring training for the participants was conducted by scene plays showing some problems in everyday life, then the participants responded and took actions in these situations by adopting new thinking and avoiding 
pro-criminal thinking that may lead them to trouble. In such excises, participants would learn problem solving skills as new thinking and coping skills. So it is not surprising that both groups remain constant in CSS scores. It is noticeable that experimental group had higher SOC mean score at Time 1 than control group, and this may be on account of the small sample size. However, the experiment group did gain improvement in SOC mean score measured by the difference between Time 1 and Time 2. The experimental group had greater improvements in GESE scores than in SOC and CSS, and this is coincident with the structure of six-session CBT program that focusing on teaching and practicing problem-solving skills.

Because the sample size was small, power calculations were conducted. The power of a statistical test is the probability to reject the null hypothesis, so the power is 1- $\beta$ (Cohen, 1988). Inspite of the non-significant difference between before and after scores on CSS for experimental group, the power is 0.36 of the test comparing the means of pre- and post-treatment scores of CSS for experimental group, which indicated that we will be able to reject the null hypothesis of $\mathrm{M}_{\text {pre }}=\mathrm{M}_{\text {post }}$ with probability 0.36 , when $\alpha=.05$ (the Type I error probability associated with this $t$ test of this null hypothesis is .05). For the differences of before and after scores on SOC and GSES, the power is 0.77 and 0.99 , revealing that we will be able to reject the null hypothesis of zero difference on SOC and GSES with probability of 0.77 and 0.99 , respectively, when $\alpha=.05$ (the Type I error probability associated with $t$ test of this null hypothesis is .05). Results of multiple regression model also revealed that experimental group would have higher likelihood to obtain greater changes on SOC and GSES. Again, the fact that experimental group obtained greater improvement in GSES than in SOC and CSS is coincident with the structure of six-session CBT program that focusing on teaching and practicing problem-solving skills.

Meanwhile, the insignificant change in CSS also eliminates the possibility of Hawthorne Effect which might cast some doubt on the improvements in SOC and GESE. During the period of delivering the CBT program, experimental and comparison group continued their routine activities scheduled by the institution as before, and they were not separated to each other. Under such circumstance, double-blind design was impossible. They might talk about the program sometimes, but the improvements of experimental group in social and problem-solving skills might not be caused by Hawthorne Effect. Both groups were tested at Time 1 and Time 2 using CSS, SOC and GSES, and significant differences between groups only appeared in SOC and GSES, but not in CSS. If Hawthorne Effect exists, experimental group should also demonstrated significant change in CSS which has the highest Cronbach's alpha of 0.898, but that did not happen. The training in the sessions and homework feedback focusing on problem-solving skills might be critical factors for those improvements in SOC and GSES.

The statistical analysis in the present study demonstrated the effectiveness of the six-session CBT program in improving young delinquents' social skills and problem-solving skills. This is informative as inefficiency of social skills and problem-solving skills are associated with criminal behavior. The six-session CBT provided sufficient training in problem-solving skills by introducing and practicing the six steps to solve a problem or cope with a stressful situation. These skills will aid the participants to adapt appropriate decision making when facing stressful situations which might trigger criminal activities as reactions, thus lead to avoidance of re-offending.

The CBT program showed positive effectiveness by teaching and enabled participants to practice relevant skills in finding a better solution when facing a problematic situation. The officers in the shelter were also impressed by the CBT program. For so many years previously, officers conduct their routine duty as to organize the delinquents to take normal education courses, most of which is led by a speaker with hundreds of audience. The speaker talks, while the delinquents sit still listening, but all feel bored. In the CBT program, many scene plays and group discussions were used, and the participants were actively involved and took part in these activities; most of them enjoyed this process. The participants also showed their potential and motivation to learn social skills via the brief CBT program. The current findings provided evidence that the problem-solving skills and social skills can be improved via the learning environment created by group activities of the structured CBT programs. Inefficiency in problem-solving skills and social skills is correlated to re-offending, and they are also crucial components in the process of constructing and reconstructing thinking patterns, thus the improvement on them might be positive for reducing the risk and likelihood of re-offending. Of course, more evidence is needed in the Chinese context.

The sample size in the present study is small. However, this pilot study has important policy and research implications for the development of correctional programs and evaluation study in China. The major obstacles including the following: program manual, trained staff, collaboration, and correction system. 
Firstly, program manual. For the purpose to evaluate a program, the existence of a program should be in the first place. Meanwhile, it is difficult to find structured CBT programs or manuals designed for incarcerated adult or young offenders, and developing such programs require huge financial and intelligent investment. Psychology knowledge would be essential in developing such manuals, but most practioners and criminologists in China are lack of such knowledge.

Secondly, trained staff. Training and delivery quality would be an serious issues. Delivering CBT programs requires experienced facilitators who have received sufficient training. Unfortunately, such facilitators are limited in Chinese correctional field. Training courses and institutions are in urgent need.

Thirdly, collaboration. Designing, implementing and evaluating CBT programs in Chinese prisons or probation agencies require the establishment of evidence-based practice, which calls for collaboration between policy makers, front line officers and researchers. There is a lack of collaboration and trust between researchers and policy makers in Chinese correctional field, and such a lack produced negative sequences: policy makers doubt that there is any use of evaluation study, and researchers could not obtain access to the field. Efforts must be made to solve the above difficulties.

Overall, the results of the pilot study were encouraging and demonstrating the potential of CBT programs to be effective treatment for young delinquents in China, but there are some limitations. The first is the small sample size. As there are only 75 male delinquents in the shelter, it is impossible to locate too many participants, and further study should be performed in other institutions. The goal of CBT programs is to change offenders' behaviors via altering their cognition. However, the improvements in cognition cannot guarantee behavioral changes all the time. In China, most ex-offenders are labeled and find it difficult to get a job when they return to the community, so many of them choose to go back to criminal career. Under such circumstance, only changing their cognition might not suffice, and other programs are also needed. Future study with follow-up period to investigate the recidivism is required.

Funding: The authors received no financial support for the research, authorship, and/or publication of this article.

Ethical approval: All procedures performed in studies involving human participants were in accordance with the ethical standards of the institutional and/or national research committee and with the 1964 Helsinki declaration and its later amendments or comparable ethical standards.

Informed consent: Informed consent was obtained from all individual participants included in the study.

\section{References}

Andrews, D. A. (1995). The psychology of criminal conduct and effective treatment. In J. McGuire (Ed.), What works: Reducing reoffending. New York: John Wiley \& Sons.

Andrews, D. A., \& Bonta, J. (1994). The Psychology of Criminal Conduct. Cincinnati, Ohio: Anderson Publishing Company.

Andrews, D. A., Bonta, J., \& Hoge, R. D. (1990). Classification for effective rehabilitation: Rediscovering psychology. Criminal Justice and Behavior, 17, 19-52.

Bandura, A. (1977). Social Learning Theory. Englewood Cliffs, New Jersey: Prentice Hall.

Beck, A. T. (1976). Cognitive Therapy and Emotional Disorders. New York: International University Press.

Berry, J. W. (Ed.). (2002). Cross-cultural psychology: Research and applications. Cambridge University Press.

Bogestad, A. J., Kettler, R. J., \& Hagan, M. P. (2010). Evaluation of a cognitive intervention program for juvenile offenders. International journal of offender therapy and comparative criminology, 54(4), 552-565.

Bolman, M. (1968). Cross-Cultural Psychotherapy. Amer. J. Psychiat, 124, 123.

Bonta, J. (1996). Risk-needs assessment and treatment. In A. T. Harland (Ed.), Choosing Correctional Options that Work: Defining the demand and evaluating the supply (pp. 18-32). Thousand Oaks, CA, US: Sage Publications, Inc.

Bureau of Guangdong Prison Management. (2009). Final report of offenders' psychology status in Guangdong prisons. Research in Crime and Reforming, 4, 14-31. [In Chinese]

Bush, J. (1995). Teaching Self-risk management to violent offenders. In J. McGuire (Ed.), What works: Reducing reoffending. New York: John Wiley \& Sons.

Bush, J., Glick, B., \& Taymans, J. (2002). Thinking for a Change. Longmont, CO: National Institute of Corrections, U.S. Department of Justice. 
Chen, W. (2009). Research in incarcerated male adult offenders' attitudes. Research in Crime and Reforming, 4, 53-61. [In Chinese]

Chui, W. H., \& Nellis, M. (Eds.). (2003). Moving Probation Forward: Evidence, Arguments and Practice. Harlow, Essex: Pearson Education.

Cohen, J. (1988). Statistical Power Analysis for the Behavioral Sciences (2nd ed.). Lawrence Erlbaum Associates, Hillsdale.

Cullen, F. T., \& Gendreau, P. (2001). Assessing correctional rehabilitation: Policy, practice and prospects. In J. Horney (Ed.), National Institute of Justice criminal justice 2000: Vol. 3, Changes in decision making and discretion in the criminal justice system. Washington, D.C.: Department of Justice, National Institute of Justice.

Duan, X. Y., \& Huang, H. (2006). The influence of family functioning, parental monitoring and self-control on youth crime. China Journal of Behavioral Medical Science, 11, 1033-1034. [In Chinese]

Ellis, A. (1962). Reason and Emotion in Psychotherapy. Secaucus, New Jersey: The Citadel Press.

Fagan, J. (1990). Social and legal policy dimensions of violent young crime. Criminal Justice and Behavior, 17.

Faul, F., Erdfelder, E., Lang, A.-G., \& Buchner, A. (2007). G*Power 3: A flexible statistical power analysis program for the social, behavioral, and biomedical sciences. Behavior Research Methods, 39, 175-191.

Forde, H. A. (2005). Evaluation of a stress inoculation training program at an Ohio male correctional institution (Doctoral dissertation). The Ohio State University.

Gendreau, P., Grant, B. A., Leipciger, M., \& Collins, S. (1979). Norms and recidivism for the MMPI and selected experimental scales on a Canadian delinquent sample. Canadian Journal of Behavioural Science, $11(1), 21-31$.

Golden, L. S. (2002). Evaluation of the efficacy of a cognitive behavioral program for offenders on probation: Think for a change (Doctoral dissertation). The University of Texas.

Golden, L. S., Gatchel, R. J., \& Cahill, M. A. (2006). Evaluating the Effectiveness of the National Institute of Corrections' "Thinking for a Change" Program among Probationers. Journal of Offender Rehabilitation, 43(2), 53-73.

Ji, S. M., \& Dai, M. S. (2004). Minnesota Multiphasic Personality Inventory-The latest research and explanation for different scales (p. 265). Beijing, Science Publication. [In Chinese]

Jing, S. J. (2009). Empirical Research on Causes of Delinquency for Urban young: A Case Study in Shanghai S District. Issues on young Crimes and Delinquency, 5, 21-24. [In Chinese]

Koehler, J. A., Lösel, F., Akoensi, T. D., \& Humphreys, D. K. (2013). A systematic review and meta-analysis on the effects of young offender treatment programs in Europe. Journal of Experimental Criminology, 1-25.

Landenberger, N., \& Lipsey, M. (2005). The positive effects of cognitive behavioral programs for offenders: A meta analysis of factors associated with effective treatment. Journal of Experimental Criminology, 1, 451-476.

Lipsey, M. W., \& Cullen, F. T. (2007). The effectiveness of correctional rehabilitation: A review of systematic reviews. Annu. Rev. Law Soc. Sci., 3, 297-320.

Little, G. L. (2003). Comparison of post-treatment recidivism rates between the NIC's Thinking for a Change Program and MRT. Cognitive-Behavioral Treatment Review, 12(2), 8-9.

Little, G. L., Robinson, K. D., \& Burnette, K. D. (1994). Treating offenders with cognitive behavioral therapy: 5-year recidivism outcome data on MRT. Cognitive Behavioral Treatment Review, 3, 1-3.

Lowenkamp, C. T., Hubbard, D., Makarios, M. D., \& Latessa, E. J. (2009). A quasi-experimental evaluation of thinking for a change: A "real-world" application. Criminal Justice and Behavior, 36(2), 137-146.

MacKenzie, D. L. (2013). First do no harm: A look at correctional policies and programs today. Journal of Experimental Criminology, 9(1), 1-17.

Marshall, B., Robinson, C., \& Cahill, M. (2004). What are they thinking? Thinking for a change two-day curriculum. Washington, DC: U.S. Department of Justice, National Institute of Corrections. Retrieved from http://nicic.gov/Library/020100 
McGlynn, A. H., Hahn, P., \& Hagan, M. P. (2013). The effect of a cognitive treatment program for male and female young offenders. International journal of offender therapy and comparative criminology, 57(9), 1107-1119.

Newman, C. F. (2010). Competency in conducting cognitive-behavioral therapy: Foundational, functional, and supervisory aspects. Psychotherapy: Theory, Research, Practice, Training, 47(1), 12.

Schwarzer, R., Bäßler, J., Kwiatek, P., Schröder, K., \& Zhang, J. X. (1997). The Assessment of Optimistic Self - beliefs: Comparison of the German, Spanish, and Chinese Versions of the General Self-efficacy Scale. Applied Psychology, 46(1), 69-88.

Sherman, L. W., Gottfredson, D., MacKenzie, D., Eck, J., Reuter, R., \& Bushway, S. (1998). Preventing crime: What works, what doesn't, what's promising 错误! 未指定书签。. National Institute of Justice: Research in Brief.

Shi, B. N. (2009). The dual nature of community correction: As punishments and social services for offenders. Journal of East China University of Science and Technology, 1, 22-27. [In Chinese]

Tseng, W. S. (2004). Culture and psychotherapy: Asian perspectives. Journal of mental health, 13(2), 151-161.

Van der Put, C. E., Stams, G. J. J. M., Hoeve, M., Deković, M., Spanjaard, H. J. M., Van der Laan, P. H., \& Barnoski, R. P. (2012). Changes in the relative importance of dynamic risk factors for recidivism during adolescence. International Journal of Offender Therapy and Comparative Criminology, 56(2), 296-316.

Wang, C. K., \& Liu, Y. (2000). Related research about trait anxiety, state anxiety and anxiety in general self-efficacy. Chinese Journal of Clinical Psychology, 8(3), 56-67. [In Chinese]

Wei, S. F., \& Duan, M. (2007). Difficulties and solution associated with labor work rules in prisons. Research in Crime and Reforming, 12, 16-19. [In Chinese]

Wong, D. S. W. (2004). Young Protection and Delinquency Prevention Policies in China. Australian and New Zealand Journal of Criminology, 37, 52-66.

Zhang C. M., \& Zou, H. (2006). Relations between personality factors and delinquency in adolescence. Advance in Psychological Science, 14(2), 241-248. [In Chinese]

\section{Note}

Note 1. According to the young Shelter Management Regulation of China, mental disorders are not allowed to be housed in young shelter.

\section{Copyrights}

Copyright for this article is retained by the author(s), with first publication rights granted to the journal.

This is an open-access article distributed under the terms and conditions of the Creative Commons Attribution license (http://creativecommons.org/licenses/by/4.0/). 